\title{
Nanocrystallization of iron-based amorphous alloys, influence of magnetization in an alternating magnetic field
}

\author{
Tetiana HULA ${ }^{1}$, Oksana HERTSYK ${ }^{1}$, Myroslava KOVBUZ ${ }^{1}$, Andrii YAKYMOVYCH ${ }^{2}$, Klaus W. RICHTER ${ }^{2}$, \\ Nataliia PANDIAK ${ }^{3}$ \\ ${ }^{1}$ Department of Physical and Colloid Chemistry, Ivan Franko National University of Lviv, \\ Kyryla i Mefodiya St. 6, 79005 Lviv, Ukraine \\ ${ }^{2}$ Department of Inorganic Chemistry - Functional Materials, University of Vienna, \\ Althanstr. 14, 1090 Vienna, Austria \\ ${ }^{3}$ Ukrainian National Forestry University, Gen. Chuprynky St. 103, 79057 Lviv, Ukraine \\ * Corresponding author. Tel.: +380-96-7701137; e-mail: djunjer1@gmail.com
}

Received August 6, 2018; accepted December 26, 2018; available on-line March 29, 2019

Nanocrystallization of iron-based amorphous alloys $\mathrm{Fe}_{82} \mathrm{Nb}_{2} \mathrm{~B}_{14} R E_{2}$, where $R E=\mathrm{Y}$, Gd, Tb, Dy, was studied by differential thermal analysis (DTA) in the temperature range from $300 \mathrm{~K}$ to $1300 \mathrm{~K}$. The structure before and after the first stage of crystallization ( $\sim 810 \mathrm{~K})$ was checked by X-ray diffraction (XRD). The measurements allowed determining the temperature and activation energy of nanocrystallization. In addition, the influence of magnetization in an alternating magnetic field on the nanocrystallization process in the amorphous alloy $\mathrm{Fe}_{82} \mathrm{Nb}_{2} \mathrm{~B}_{14} \mathrm{Gd}_{2}$ was studied. The electrochemical changes caused by the alternating magnetic field were investigated by potentiometry and voltammetry.

Amorphous and nanocrystalline alloys / Nanocrystallization / Differential thermal analysis / Alternating magnetic field / Electrochemical properties

\section{Introduction}

Amorphous and nanocrystalline ferromagnetic alloys based on iron are materials with unique physicochemical properties, which explains their extended application. Such alloys are of great importance since in these types of material enhancement of the effect of soft magnetic properties can be observed [1-5].

It should be emphasized that amorphous materials are homogeneous and do not contain grains or other structural elements of noticeable size. The alloys are obtained as a result of rapid cooling of the melts and, in their nature, remain closer to solid solutions than to inhomogeneous sediments. Actually, they may contain chemical and structural inhomogeneities, especially in the subsurface layers with plane areas and peaks, the heights of which may reach $10 \mathrm{~nm}$. The size of certain inhomogeneities may be even larger $(0.2-1.0 \mu \mathrm{m})$, but then the surface defects may be smaller $(<10 \mathrm{~nm})$. Since the changes in the domain boundaries, due to the presence of defects, are, in fact, very small, the magnetic permeability remains quite high $[6,7]$.

Soft magnetic properties are connected with particular structural changes taking place during thermal annealing at temperatures close to crystallization, and are usually explained by magnetic interactions between iron nanograins. Indeed, a microstructure with iron nanograins embedded in an amorphous surrounding smoothes out the magnetic anisotropy and causes an enhancement of the magnetic permeability. It is also known that, in the case of $\mathrm{Fe}-\mathrm{Nb}-\mathrm{B}$ (NANOPERM type) amorphous alloys, such an effect occurs in the relaxed amorphous phase, without formation of a nanostructure.

It is necessary to establish the principal factors responsible for the structural stability and nanocrystallization of amorphous alloys under the actual operating conditions of magnetic devices, and their functional characteristics as a whole. It is known that the addition of boron, and other amorphizing agents, significantly enhances the stability of the amorphous phase based on Fe [8,9]. However, the mechanism of the action of the alloying atoms is not completely clarified and requires additional investigations by both theoretical and experimental methods. In particular, it is important to analyze the influence of annealing and different magnetic fields on the physico-chemical properties of amorphous alloys. 


\section{Experimental}

Experiments were carried out on the following amorphous metallic alloys (AMA) based on iron: $\mathrm{Fe}_{82} \mathrm{Nb}_{2} \mathrm{~B}_{14} \mathrm{Y}_{2}, \mathrm{Fe}_{82} \mathrm{Nb}_{2} \mathrm{~B}_{14} \mathrm{Gd}_{2}, \quad \mathrm{Fe}_{82} \mathrm{Nb}_{2} \mathrm{~B}_{14} \mathrm{~Tb}_{2}$, and $\mathrm{Fe}_{82} \mathrm{Nb}_{2} \mathrm{~B}_{14} \mathrm{Dy}_{2}$. The AMA were obtained by melt spinning in helium atmosphere onto a copper wheel with a circumferential speed of about $30 \mathrm{~m} / \mathrm{s}$. The purities of the initial metals were the following: Fe (99.99 wt.\%), Y (99.96 wt.\%), Gd (99.96 wt.\%), $\mathrm{Tb}$ (99.96 wt.\%), and Dy (99.96 wt.\%). The alloys were obtained in the Kyiv G.V. Kurdyumov Institute for Metal Physics of NASU, in the form of strips with thicknesses of $20-25 \mu \mathrm{m}$ and widths of 1-3 mm.

The microstructures and elemental compositions of the initial samples were investigated using a scanning electron microscope (SEM) Zeiss Supra 55 VP ESEM.

Crystallization of the obtained alloys was examined with the use of differential thermal analysis (DTA, Netzsch DTA 404PC) technique. The samples (about 20-25 mg of alloy) were encapsulated into an alumina (aluminum oxide) crucible and heated up to $1123-1373 \mathrm{~K}$ at different constant heating rates $(5,8$, 15 , and $25 \mathrm{~K} / \mathrm{min}$ ). The same empty alumina crucible was used as reference plate. The $\mathrm{Fe}_{82} \mathrm{Nb}_{2} \mathrm{~B}_{14} \mathrm{Gd}_{2}$ sample was also analyzed after magnetization in a low-frequency $(50 \mathrm{~Hz}, 0.43 \mathrm{~T})$ alternating magnetic field (AMF) for 30, 90, and $210 \mathrm{~min}$.

Structural investigations were carried out by X-ray diffraction (XRD), using a Bruker D8 diffractometer with $\mathrm{Cu} K_{\alpha}$-radiation. The XRD spectra were measured for samples in the as-quenched state and after heating up to $850 \mathrm{~K}$ with a heating rate of $15 \mathrm{~K} / \mathrm{min}$ (samples used in DTA experiments), i.e. after the first stage of crystallization.

To evaluate the corrosion resistance of the amorphous alloys, we used the chronopotentiometric method, which makes it possible to study spontaneous electrochemical processes running on the electrodesolution boundary according to the changes in the free potential $(E)$. The changes in the free potential of the AMA-electrode were recorded with respect to a $\mathrm{Cl}^{-}|\mathrm{AgCl}| \mathrm{Ag}$ (sat) reference electrode. The working electrode was an amorphous metallic alloy strip and the duration was $20 \mathrm{~min}$. The initial $\left(E_{0}\right)$ and final $\left(E_{\mathrm{f}}\right)$ values of the potential were determined from the dependence $E=\mathrm{f}(t)$.
For cyclic voltammetry, we used a threeelectrode scheme, in which, in parallel with the working and reference electrodes, we used an auxiliary electrode in the form of a platinum plate. The potentials were scanned in the range from -1.5 to $+0.5 \mathrm{~V}$ at a sweep rate of $20 \mathrm{mV} / \mathrm{s}$. The electrochemical investigations were performed using an IPM PC-R Jaissle Potentiostat/Galvanostat in a $0.05 \mathrm{M}$ aqueous solution of $\mathrm{H}_{2} \mathrm{SO}_{4}$ [10].

\section{Results and discussion}

The properties of amorphous alloys depend both on their elemental composition and on the structural state. The elemental compositions of the investigated Fe-based amorphous alloys doped by rare-earth elements were determined by energy-dispersive X-ray analysis, on a scanning electron microscope (Fig. 1, Table 1).

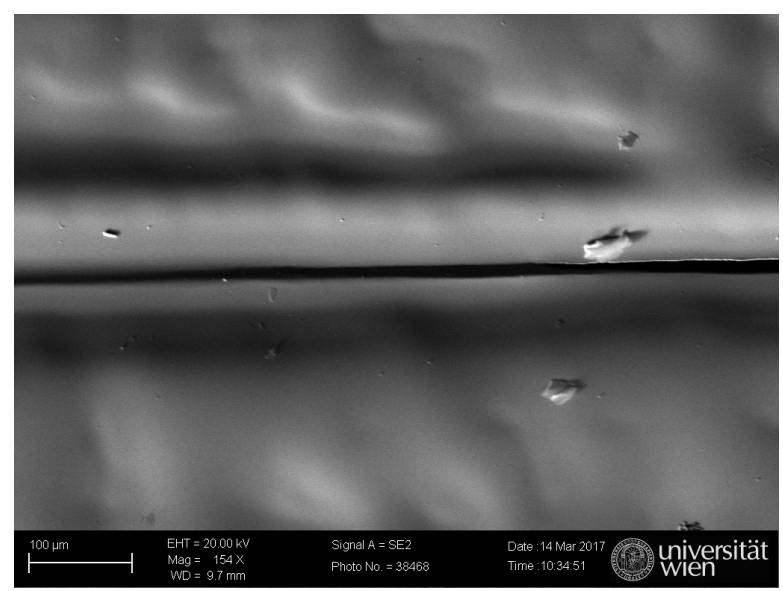

Fig. 1 Microphoto of the surface of the AMA electrode $\mathrm{Fe}_{82} \mathrm{Nb}_{2} \mathrm{~B}_{14} \mathrm{Gd}_{2}$.

Fig. 2 shows DTA curves in the temperature range from $600 \mathrm{~K}$ to $1000 \mathrm{~K}$ (heating rate $15 \mathrm{~K} / \mathrm{min}$ ) for all the investigated alloys. The complete curves $(300 \mathrm{~K}-1300 \mathrm{~K})$ revealed only one stage of crystallization i.e. one endothermal peak up to the temperature of $850 \mathrm{~K}$.

Table 1 Chemical composition of the surface of the Fe-based amorphous metallic alloys studied here.

\begin{tabular}{c|c|c|c|c|c|c|c}
\hline \multirow{2}{*}{ Sample } & \multicolumn{7}{|c}{ Chemical element, at.\% } \\
\cline { 2 - 8 } & Fe & Nb & B & Y & Gd & Tb & Dy \\
\hline F1 & 82.34 & 1.76 & 13.54 & 2.36 & - & - & - \\
F2 & 82.32 & 1.95 & 13.82 & - & 1.91 & - & - \\
F3 & 82.33 & 1.83 & 13.86 & - & - & 1.98 & - \\
F4 & 82.29 & 1.77 & 13.78 & - & - & - & 2.16 \\
\hline
\end{tabular}




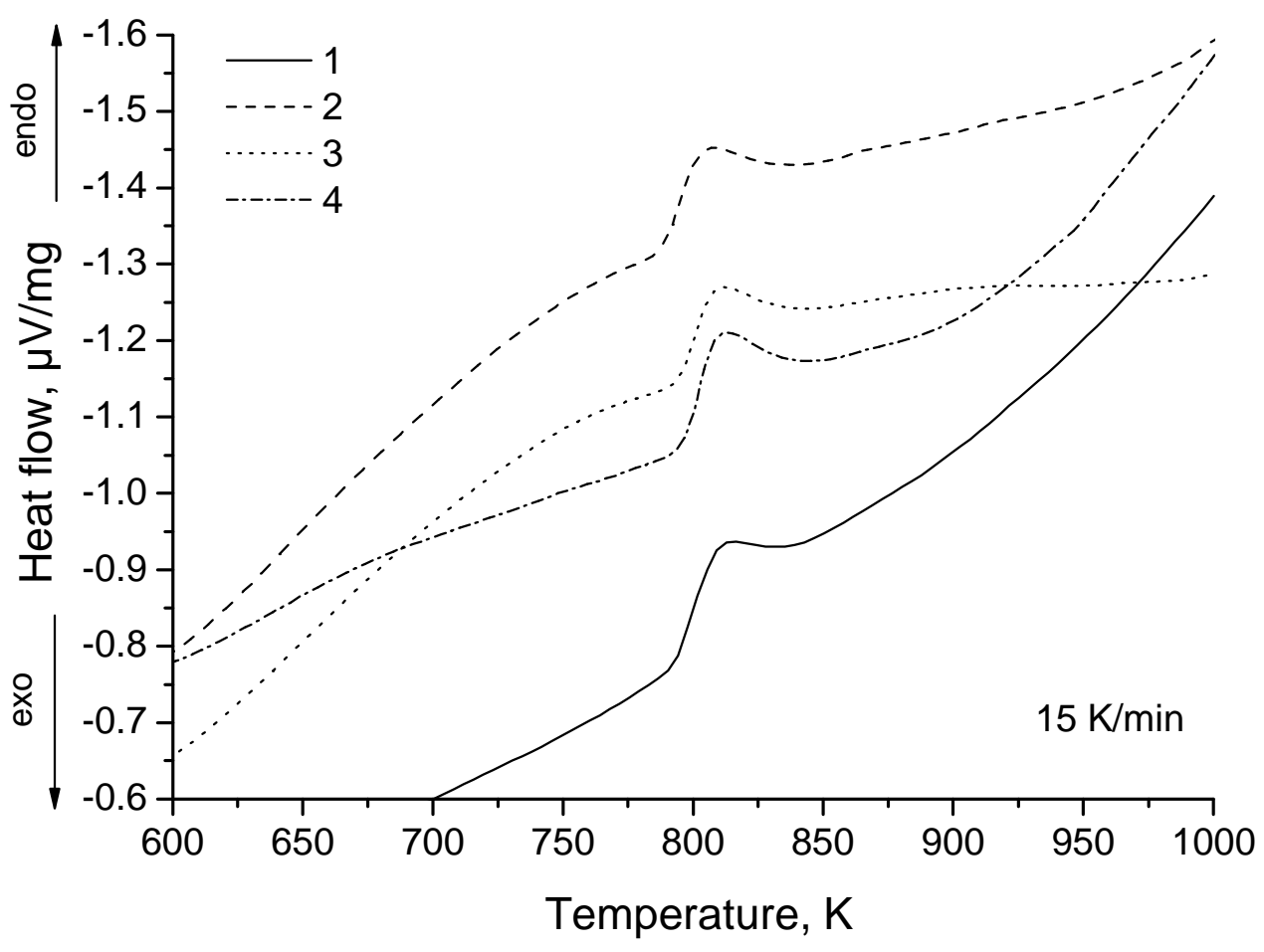

Fig. 2 DTA curves for the Fe-based amorphous alloys: $1-\mathrm{Fe}_{82} \mathrm{Nb}_{2} \mathrm{~B}_{14} \mathrm{Y}_{2}, 2-\mathrm{Fe}_{82} \mathrm{Nb}_{2} \mathrm{~B}_{14} \mathrm{Gd}_{2}$, $3-\mathrm{Fe}_{82} \mathrm{Nb}_{2} \mathrm{~B}_{14} \mathrm{~Tb}_{2}, 4-\mathrm{Fe}_{82} \mathrm{Nb}_{2} \mathrm{~B}_{14} \mathrm{Dy}_{2}$ (heating rate $15 \mathrm{~K} / \mathrm{min}$ ).

Table 2 Activation energies $E_{\mathrm{a}}$ and peak temperatures $T_{\mathrm{p}}$ determined by DTA.

\begin{tabular}{|c|c|c|c|c|}
\hline Amorphous alloy & Heating rate, $\mathrm{K} / \mathrm{min}$ & $T_{\mathrm{p}}, \mathrm{K}$ & $\begin{array}{c}E_{\mathrm{a}}, \mathrm{kJ} / \mathrm{mol} \\
\text { (Kissinger) } \\
\end{array}$ & $\begin{array}{c}E_{\mathrm{a}}, \mathrm{kJ} / \mathrm{mol} \\
\text { (Ozawa) }\end{array}$ \\
\hline \multirow{4}{*}{$\mathrm{Fe}_{82} \mathrm{Nb}_{2} \mathrm{~B}_{14} \mathrm{Y}_{2}$} & 5 & 803 & \multirow{4}{*}{472.3} & \multirow{4}{*}{485.8} \\
\hline & 8 & 807 & & \\
\hline & 15 & 813 & & \\
\hline & 25 & 817 & & \\
\hline \multirow{4}{*}{$\mathrm{Fe}_{82} \mathrm{Nb}_{2} \mathrm{~B}_{14} \mathrm{Gd}_{2}$} & 5 & 798 & \multirow{4}{*}{527.3} & \multirow{4}{*}{539.1} \\
\hline & 8 & 804 & & \\
\hline & 15 & 808 & & \\
\hline & 25 & 815 & & \\
\hline \multirow{4}{*}{$\mathrm{Fe}_{82} \mathrm{Nb}_{2} \mathrm{~B}_{14} \mathrm{~Tb}_{2}$} & 5 & 801 & \multirow{4}{*}{535.5} & \multirow{4}{*}{544.0} \\
\hline & 8 & 804 & & \\
\hline & 15 & 809 & & \\
\hline & 25 & 811 & & \\
\hline \multirow{4}{*}{$\mathrm{Fe}_{82} \mathrm{Nb}_{2} \mathrm{~B}_{14} \mathrm{Dy}_{2}$} & 5 & 802 & \multirow{4}{*}{529.0} & \multirow{4}{*}{549.1} \\
\hline & 8 & 806 & & \\
\hline & 15 & 812 & & \\
\hline & 25 & 816 & & \\
\hline
\end{tabular}

It may be noticed that the temperature of the DTA peak, $T_{\mathrm{p}}$, which corresponds to the highest crystallization rate, depends on the rare-earth alloying additive. The lowest value of $T_{\mathrm{p}}$ was observed for the $\mathrm{Fe}_{82} \mathrm{Nb}_{2} \mathrm{~B}_{14} \mathrm{Gd}_{2}$ alloy (808 K) and the highest one for the $\mathrm{Fe}_{82} \mathrm{Nb}_{2} \mathrm{~B}_{14} \mathrm{Y}_{2}$ alloy $(813 \mathrm{~K})$. The same tendency was observed for the other heating rates $(5 \mathrm{~K} / \mathrm{min}, 8 \mathrm{~K} / \mathrm{min}$, and $25 \mathrm{~K} / \mathrm{min}$ ), with the reservation that the peak positions are shifted to higher temperatures for higher heating rates. Taking into consideration this temperature shift and using the Kissinger method and Ozawa's method [11], the activation energy $E_{\mathrm{a}}$ was calculated for the studied alloys (Table 2). The corresponding straight lines for $\mathrm{Fe}_{82} \mathrm{Nb}_{2} \mathrm{~B}_{14} \mathrm{Y}_{2}$ are shown in Fig. 3. 

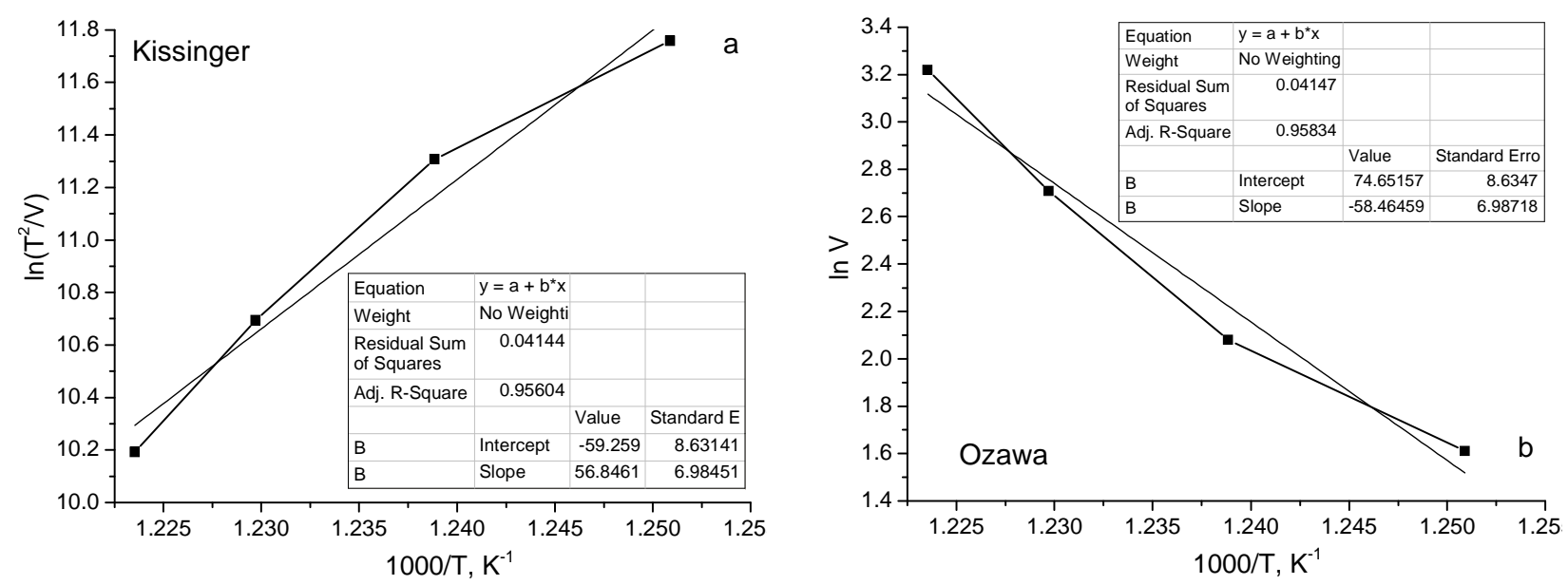

Fig. 3 Arrhenius plot $\ln \left(T^{2} / V\right)$ vs. $1000 / T$ (a) and $\ln (V)$ vs. $1000 / T$ (b) for the crystallization of the AMA $\mathrm{Fe}_{82} \mathrm{Nb}_{2} \mathrm{~B}_{14} \mathrm{Y}_{2}$ according to the Kissinger (a) and Ozawa's (b) method.

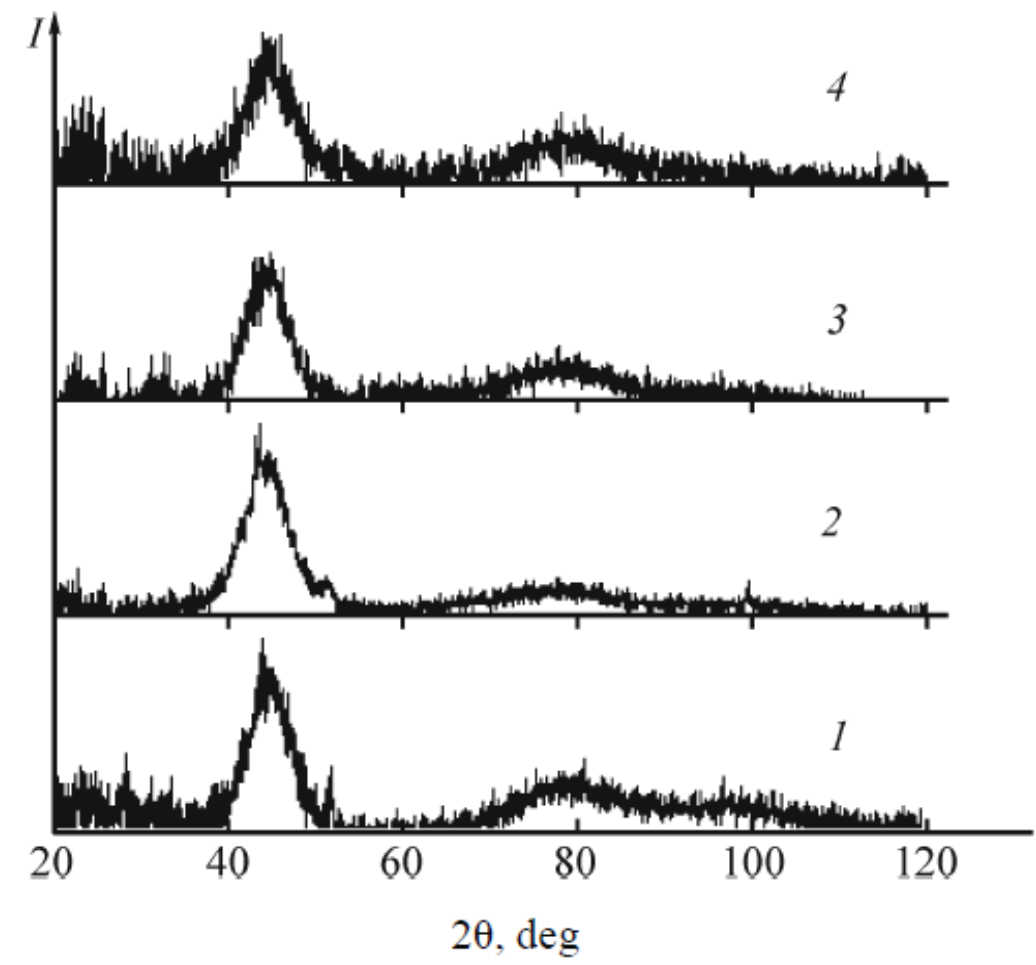

Fig. 4 X-ray diffraction patterns of the initial AMA samples: Intensity (I) vs. Bragg angle $(2 \theta)$. $1-\mathrm{Fe}_{82} \mathrm{Nb}_{2} \mathrm{~B}_{14} \mathrm{Y}_{2}, 2-\mathrm{Fe}_{82} \mathrm{Nb}_{2} \mathrm{~B}_{14} \mathrm{Gd}_{2}, 3-\mathrm{Fe}_{82} \mathrm{Nb}_{2} \mathrm{~B}_{14} \mathrm{Dy}_{2}$, and $4-\mathrm{Fe}_{82} \mathrm{Nb}_{2} \mathrm{~B}_{14} \mathrm{~Tb}_{2}$.

XRD patterns obtained for the samples in the as-quenched state are presented in Fig. 4. In all four cases the XRD diffractograms are typical of ironbased amorphous alloys, and do not show any characteristic of a crystalline structure.

The XRD patterns obtained for the samples heated up to $850 \mathrm{~K}$ with a heating rate of $15 \mathrm{~K} / \mathrm{min}$, i.e. after the first stage of crystallization, revealed lines corresponding to nanocrystalline iron and the iron boride $\mathrm{Fe}_{23} \mathrm{~B}_{6}[12,13]$.
After magnetization in an alternating magnetic field, the $\mathrm{Fe}_{82} \mathrm{Nb}_{2} \mathrm{~B}_{14} \mathrm{Gd}_{2}$ sample showed the same peak temperature corresponding to the nanocrystallization process, but the heat flow depended on the time kept in the magnetic field (Fig. 5). No significant structural changes were noted on the XRD patterns after exposure to the alternating magnetic field. But magnetization caused some noticeable changes in the corrosion resistance. 


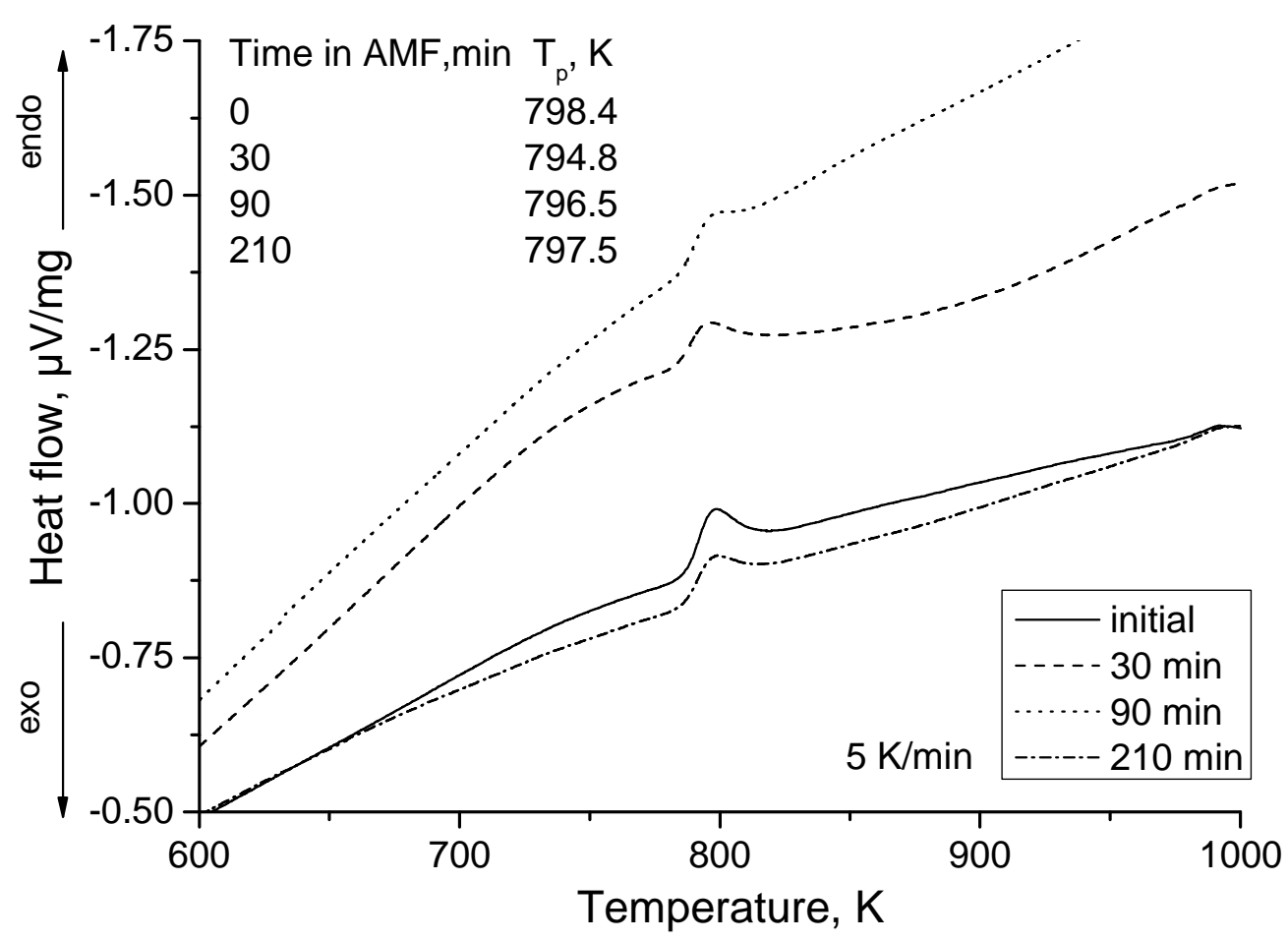

Fig. 5 DTA curves of the $\mathrm{Fe}_{82} \mathrm{Nb}_{2} \mathrm{~B}_{14} \mathrm{Gd}_{2}$ sample after $(0 \div 210)$ min magnetization in an alternating magnetic field (heating rate $5 \mathrm{~K} / \mathrm{min}$ ).

Table 3 Results of potentiometry $\left(0.05 \mathrm{M} \mathrm{H}_{2} \mathrm{SO}_{4}\right)$ of the contact and external sides of $\mathrm{AMA} \mathrm{Fe}{ }_{82} \mathrm{Nb}_{2} \mathrm{~B}_{14} \mathrm{Gd}_{2}$, before and after magnetization in an alternating magnetic field.

\begin{tabular}{c|c|c|c|c}
\hline AMF, $\min$ & Surface & $E_{0}, \mathrm{~V}$ & $E_{\mathrm{f}}, \mathrm{V}$ & $\Delta E=E_{\mathrm{f}}-E_{0}, \mathrm{~V}$ \\
\hline \multirow{2}{*}{0} & contact & -0.42 & -0.44 & -0.02 \\
\cline { 2 - 5 } & external & -0.46 & -0.44 & 0.02 \\
\hline \multirow{2}{*}{210} & contact & -0.51 & -0.53 & -0.02 \\
\cline { 2 - 5 } & external & -0.56 & -0.53 & 0.03 \\
\hline
\end{tabular}

Fe-based amorphous alloys show high corrosion resistance in a $0.05 \mathrm{M} \mathrm{H}_{2} \mathrm{SO}_{4}$ aqueous solution [14], so we used this aggressive environment for the electrochemical analysis. In the electrochemical investigations the contact and external surfaces of the AMA strips were distinguished. According to the results of the chronopotentiometry (Table 3) of $\mathrm{Fe}_{82} \mathrm{Nb}_{2} \mathrm{~B}_{14} \mathrm{Gd}_{2}$ AMA, previously magnetized in AMF for $210 \mathrm{~min}$, the potential of the contact side was shifted to more negative values, i.e. the corrosion resistance of was reduced. For the external side the potential was shifted to less negative values, which represents an increase of the corrosion resistance. However, after $20 \mathrm{~min}$ in the aggressive media, both values became similar. The same was observed for the sample that had not been exposed to an alternating magnetic field.
Table 4 and Fig. 6 show the results of cyclic voltammetry in the range from $-1.5 \mathrm{~V}$ to $+0.5 \mathrm{~V}$ in a $0.05 \mathrm{M}$ aqueous solution of $\mathrm{H}_{2} \mathrm{SO}_{4}$ of the AMA $\mathrm{Fe}_{82} \mathrm{Nb}_{2} \mathrm{~B}_{14} \mathrm{Gd}_{2}$ sample magnetized in $\mathrm{AMF}$ for $210 \mathrm{~min}$. After exposure to AMF the corrosion potentials of the amorphous alloys were shifted to the cathode zone and the corrosion currents became higher. This means that the alternating magnetic field reduced the corrosion resistance of both the external and contact sides of the AMA.

Magnetization of the AMA $\mathrm{Fe}_{82} \mathrm{Nb}_{2} \mathrm{~B}_{14} \mathrm{Gd}_{2}$ changed not only the corrosion resistance, but also the electrical conductivity of the sample (Fig. 7). After exposure to the alternating magnetic field, the sample showed higher resistivity, which increased with increasing time of exposure. 
Table 4 Corrosion parameters $\left(0.05 \mathrm{M} \mathrm{H}_{2} \mathrm{SO}_{4}\right)$ of the contact and external sides of $\mathrm{AMA} \mathrm{Fe}_{82} \mathrm{Nb}_{2} \mathrm{~B}_{14} \mathrm{Gd}_{2}$ before and after magnetization in AMF, for different numbers of cycles $(v=20 \mathrm{mV} / \mathrm{s})$.

\begin{tabular}{c|c|c|c|c|c|c|c|c}
\hline \multirow{2}{*}{ Cycle } & \multicolumn{3}{|c|}{ Initial } & \multicolumn{4}{c}{ AMF for 210 min } \\
\cline { 2 - 9 } & \multicolumn{2}{|c|}{ Contact } & \multicolumn{2}{|c|}{ External } & \multicolumn{2}{c}{ Contact } & \multicolumn{2}{c}{ External } \\
\cline { 2 - 9 } & $E_{\text {cor }}, \mathrm{V}$ & $i_{\text {cor }} \cdot 10^{3}, \mathrm{~A} / \mathrm{cm}^{2}$ & $E_{\text {cor }}, \mathrm{V}$ & $i_{\text {cor }} \cdot 10^{3}, \mathrm{~A} / \mathrm{cm}^{2}$ & $E_{\text {cor }}, \mathrm{V}$ & $i_{\text {cor }} \cdot 10^{3}, \mathrm{~A} / \mathrm{cm}^{2}$ & $E_{\text {cor }}, \mathrm{V}$ & $i_{\text {cor }} \cdot 10^{3}, \mathrm{~A} / \mathrm{cm}^{2}$ \\
\hline 1 & -0.56 & 14.38 & -0.56 & 27.18 & -0.45 & 16.01 & -0.51 & 29.75 \\
5 & -0.52 & 39.83 & -0.52 & 32.59 & -0.54 & 59.85 & -0.53 & 37.75 \\
10 & -0.55 & 6.05 & -0.53 & 6.75 & -0.56 & 10.00 & -0.54 & 26.87 \\
\hline
\end{tabular}
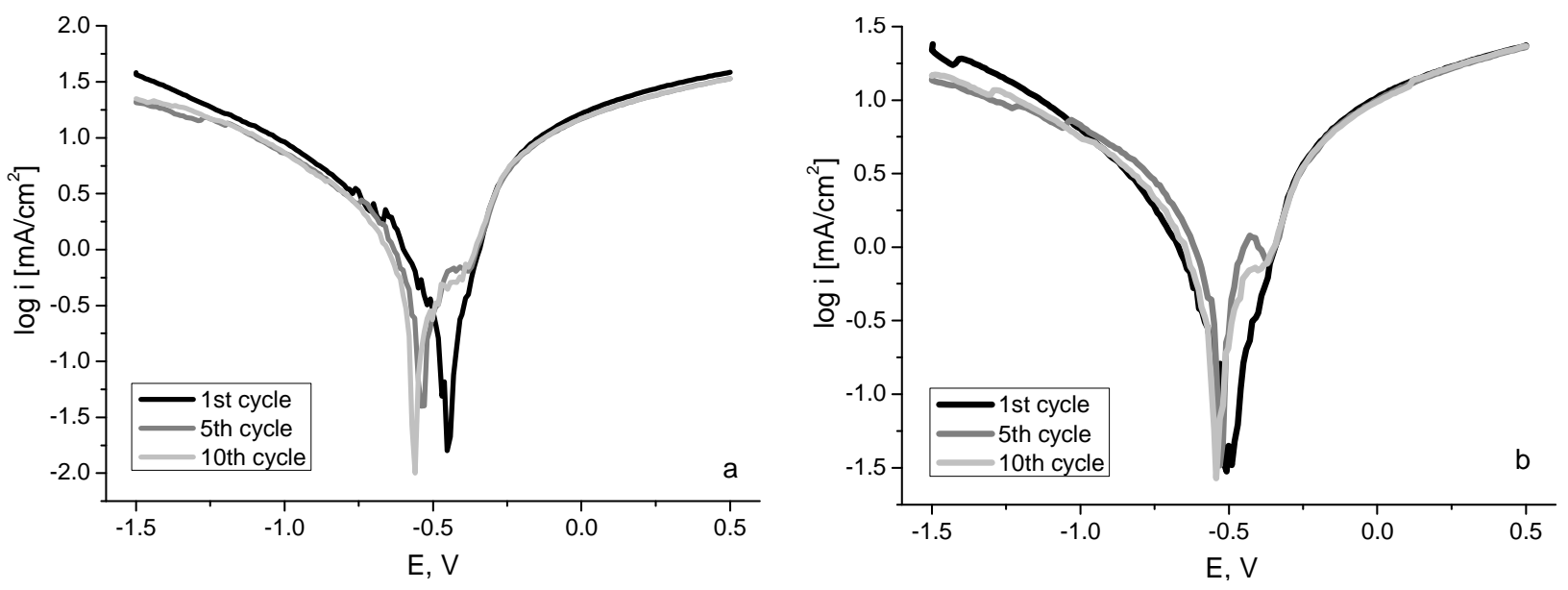

Fig. 6 Voltammetry curves $\left(0.05 \mathrm{M} \mathrm{H}_{2} \mathrm{SO}_{4}\right)$ of the contact (a) and external (b) sides of $A M A \mathrm{Fe}_{82} \mathrm{Nb}_{2} \mathrm{~B}_{14} \mathrm{Gd}_{2}$ after 210 min magnetization in an alternating magnetic field.

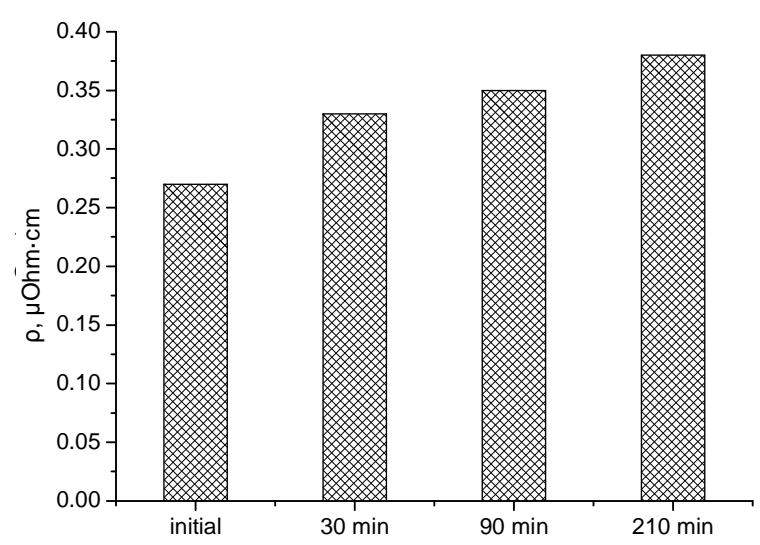

Fig. 7 Resistivity of AMA $\mathrm{Fe}_{82} \mathrm{Nb}_{2} \mathrm{~B}_{14} \mathrm{Gd}_{2}$, before and after magnetization in AMF.

\section{Conclusions}

The crystallization of $\mathrm{Fe}_{82} \mathrm{Nb}_{2} \mathrm{~B}_{14} R E_{2}(R E=\mathrm{Y}, \mathrm{Gd}$, $\mathrm{Tb}$, and Dy) amorphous metallic alloys proceeds in two stages. The first stage occurs at a temperature of about $810 \mathrm{~K}$ and is due to nanocrystallization of iron and formation of the iron boride $\mathrm{Fe}_{23} \mathrm{~B}_{6}$. Full crystallization presumably takes place at higher temperatures.
No significant structural changes, or changes of the temperature corresponding to the nanocrystallization process, were observed for amorphous $\mathrm{Fe}_{82} \mathrm{Nb}_{2} \mathrm{~B}_{14} \mathrm{Gd}_{2}$ after magnetization in an alternating magnetic field.

The alternating magnetic field reduced the corrosion resistance of the external and contact sides of the AMA $\mathrm{Fe}_{82} \mathrm{Nb}_{2} \mathrm{~B}_{14} \mathrm{Gd}_{2}$ in a $0.05 \mathrm{M}$ aqueous solution of $\mathrm{H}_{2} \mathrm{SO}_{4}$.

The amorphous alloy $\mathrm{Fe}_{82} \mathrm{Nb}_{2} \mathrm{~B}_{14} \mathrm{Gd}_{2}$ having been exposed to an alternating magnetic field showed higher resistivity.

\section{References}

[1] M.E. McHenry, M.A. Willard, D.E. Laughin, Prog. Mater. Sci. 44 (1999) 291-433.

[2] G. Haneczok, J. Rasek, Def. Diffus. Forum 224-225 (2004) 13-26.

[3] G. Haneczok, J.E. Frąckowiak, A. Chrobak, P. Kwapuliński, J. Rasek, Phys. Status Solidi A 202 (2005) 2574-2581.

[4] T. Naohara, Phil. Mag. Lett. 78 (1998) 229-234.

[5] A. Chrobak, G. Haneczok, Z. Stokłosa, P. Kwapuliński, J. Rasek, G. Chełkowska, Phys. Status Solidi A 196(1) (2003) 248-251. 
[6] A. Malozemov, J. Slonczewski, Domain Walls in Bubble Materials, Academic Press, NY, 1979.

[7] A.P. Shpak, A.B. Shevchenko, Coll. Abstr. Conf. Nanosized Systems (NANSYS 2004), Kyiv, 2004, p. 303 (in Ukrainian).

[8] I.V. Zolotukhin, Progress in Physical Science, Nauka, Moscow, 1990 (in Russian).

[9] O.M. Hertsyk, M.O. Kovbuz, L.M. Bednars'ka, N. Kavchak, Visn. Lviv. Univ., Ser. Khim. 43, (2003) 205-208 (in Ukrainian).

[10] O.M. Hertsyk, M.O. Kovbuz, O.A. Ezers'ka, T.H. Pereverzeva, Mater. Sci. 47(3) (2011) 401-407.
[11] S. Ahmadi, H.R. Shahverdi, S.S. Saremi, J. Mater. Sci. Technol. 27(6) (2011) 497-502.

[12] A. Fernández-Martinez, P. Gorria, G.J. Cuello, J.D. Santos, M.J. Pérez, J. Non-Cryst. Solids 353 (2007) 855-858.

[13] M.V. Susic, S.U. Pan, A.M. Maricic, J. Mater. Sci. 25(2) (1990) 1369-1372.

[14] O. Hertsyk, T. Pereverzieva, M. Kovbuz, S. Shurko, N. Sen'kiv, Visn. Lviv. Univ., Ser. Khim. 59(2) (2018) 499-505 (in Ukrainian). 